\title{
UNIVERSITYOF
}

FORWARD

THINKING

WESTMINSTER用

WestminsterResearch

http://www.westminster.ac.uk/westminsterresearch

Hybrid Manufactured Waveguide Resonators and Filters for mm-

Wave Applications

Jankovic, U., Mohottige, N., Glubokov, O. and Budimir, D.

This is a copy of the author's accepted version of a paper subsequently published in the proceedings of the 2017 IEEE MTT-S International Microwave Workshop Series on Advanced Materials and Processes for RF and THz Applications, Pavia, Italy, 22 to 24 September 2017.

It is available online at:

https://dx.doi.org/10.1109/IMWS-AMP.2017.8247360

(C) 2017 IEEE . Personal use of this material is permitted. Permission from IEEE must be obtained for all other uses, in any current or future media, including reprinting/republishing this material for advertising or promotional purposes, creating new collective works, for resale or redistribution to servers or lists, or reuse of any copyrighted component of this work in other works.

The WestminsterResearch online digital archive at the University of Westminster aims to make the research output of the University available to a wider audience. Copyright and Moral Rights remain with the authors and/or copyright owners.

Whilst further distribution of specific materials from within this archive is forbidden, you may freely distribute the URL of WestminsterResearch: ((http://westminsterresearch.wmin.ac.uk/)).

In case of abuse or copyright appearing without permission e-mail repository@westminster.ac.uk 


\section{Hybrid Manufactured Waveguide Resonators and Filters for mm-Wave Applications}

\author{
Uros Jankovic, Nandun Mohottige and Djuradj Budimir \\ Wireless Communications Research Group \\ University of Westminster \\ 115 New Cavendish Street, London, UK \\ d.budimir@wmin.ac.uk
}

\author{
Oleksandr Glubokov \\ MST, School of Electrical Engineering \\ KTH Royal Institute of Technology \\ Stockholm, Sweden
}

\begin{abstract}
Additive and hybrid manufactured waveguide resonators and bandpass filters for $\mathrm{mm}$-wave applications are presented. A $K_{a}$ band 3D printed waveguide resonator with inductive windows and $28 \mathrm{GHz} 5 \mathrm{G}$ band hybrid manufactured waveguide resonator and bandpass filter are designed. Hybrid manufacturing combines 3D polymer printing and conventional metal processing technologies. In order to illustrate the accuracy of the design, a 3D printed waveguide transmission line and resonator with the resonant frequency of $33 \mathrm{GHz}$ are fabricated and tested.
\end{abstract}

Keywords-3D printing; hybrid manufacturing; waveguide resonators; waveguide filters; PLA.

\section{INTRODUCTION}

Ongoing fast growth of additive manufacturing is now finding wide applications in mm-wave 5G [1-3] wireless and satellite systems. 3D printing can be applied to many materials, categorized as metallic and non-metallic. Metallic additive manufacturing of microwave mm-wave filter components, such as by selective laser melting (SLM) method with alloy powder, has been tested in practice so far [4], and non-metallic one using stereolithography (SLA) method with ceramic-filled resin is available as well for high-end products [5]. Although these alternatives have more advanced structure complexity, shorter turn-around time, produce less energy and material waste and can have reduced weight, the performance is still not exactly at the level of subtractive manufactured components of the same shape and price advantage is questionable.

3D printing with plastics has started being applied as inexpensive and lightweight alternative to conventional manufacturing of filter and other passive microwave components, mostly again with SLA method [6,7]. Its downsides are thermal and mechanical sensitivity. Universal problem with additive manufacturing is high surface roughness, although some technologies like SLA can produce finer details and smoother surfaces. Also, non-metallic 3D printing requires metal plating.

Here, we use the most popular consumer 3D printing technology, fused deposition modeling (FDM), also known as fused filament fabrication (FFF), to print the waveguide housing and dielectric filling supporting the filter structure, which geometries would otherwise be very hard to realize. Ecologically friendly polylactic acid (PLA) bioplastic is used as
FDM filament that is heated up to the melting point, extruded through the printer nozzle, and deposited layer by layer onto a flat surface of the printer glass build plate. However, other thermoplastics such as acrylonitrile butadiene styrene (ABS) or nylon could be used as well.

Furthermore, in the case of hybrid manufacturing using conventional waveguide housing, there is no need for metal plating and surface roughness has miniscule effect onto filter performance as standard waveguide housing is used and metal elements inside the waveguide are fabricated from a metal sheet using a milling unit. Thus, there is no problem in using FDM instead of SLA as technology with currently more affordable printers and materials as well as easier for maintenance.

\section{RESONATORS AND FILTERSS}

\section{A. 3D printed Waveguide Resonators}

Fig. 1 shows the layout of a 3D printed waveguide resonator structure at $\mathrm{K}_{\mathrm{a}}$ band inside WR-28 PLA dielectric waveguide housing with inner dimensions of $7.112 \mathrm{~mm} \times 3.556 \mathrm{~mm}$ cut along the center E-plane. This half-wave resonator is $5.91 \mathrm{~mm}$ long.

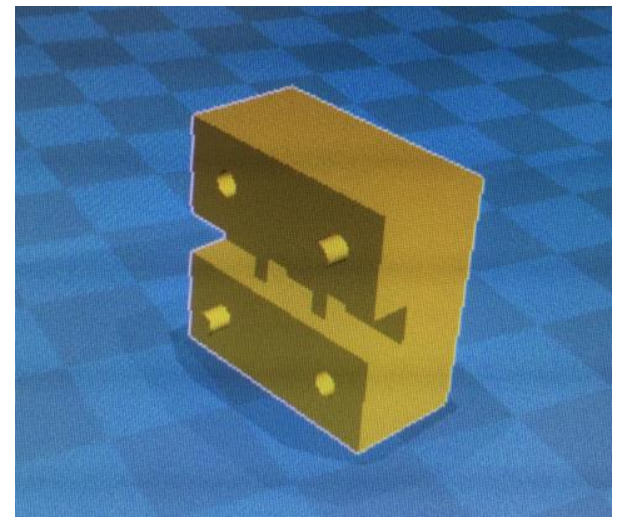

Fig. 1. Layout of a waveguide resonator in free to download Cura 3D Printing Slicing Software.

The waveguide housing was covered three times with metallic paint, having curing time of $2 \mathrm{~h}$ for each coating layer. The metallic paint used is Ferro electronic materials 62900341 (L204N) silver conductive lacquer [8]. The fabricated inductive 
coupled waveguide resonator is shown in Fig. 2 and its simulated frequency responses in Fig. 3. The measured $\mathrm{S}_{21}$-parameters of the $3 \mathrm{D}$ printed waveguide transmission line and waveguide resonator are given in Fig. 4.

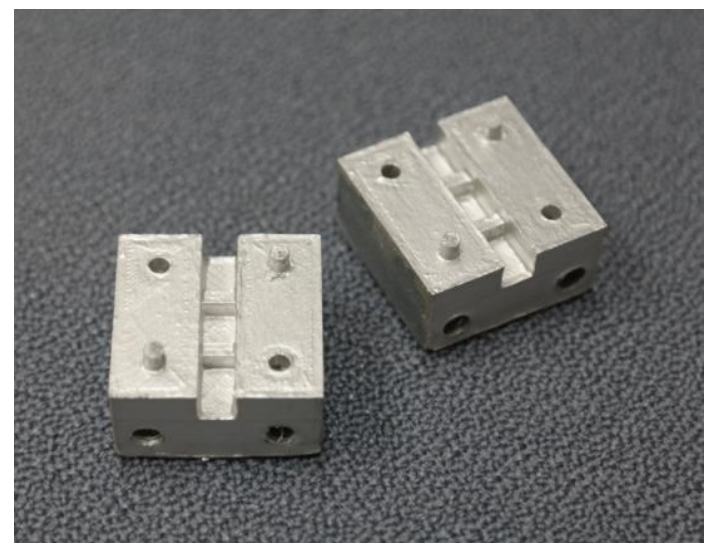

Fig. 2. Photograph of the 3D printed waveguide resonator.

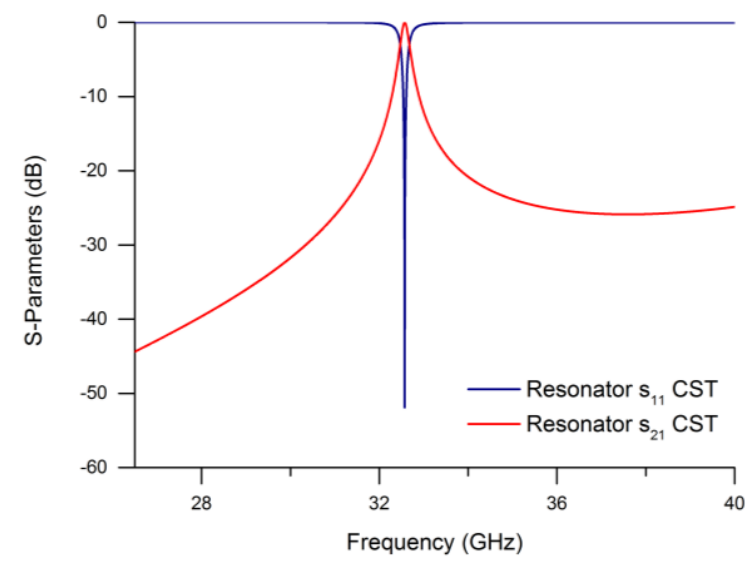

Fig. 3. Simulated S-parameters of the 3D printed waveguide resonator

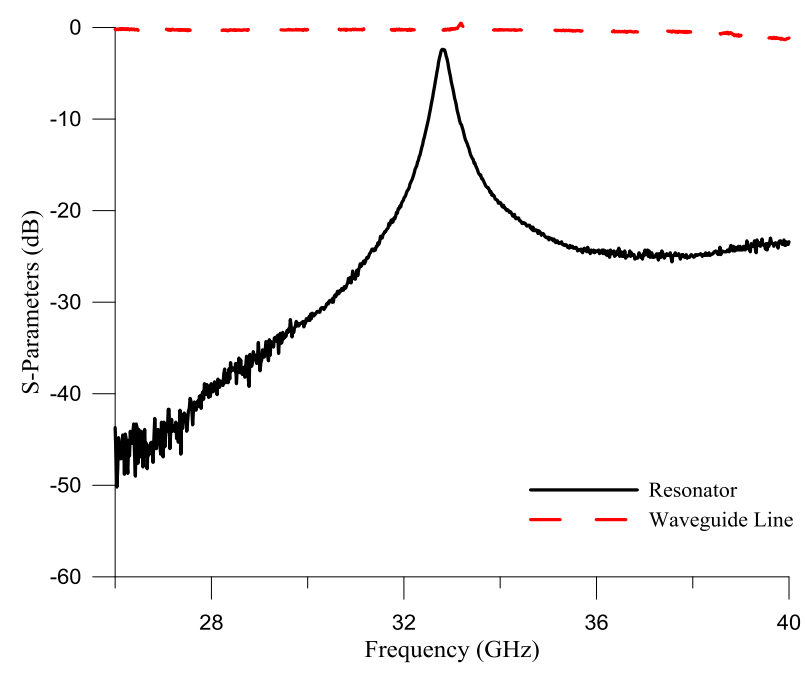

Fig. 3. Measured $S_{21}$-parameters of the $3 D$ printed waveguide transmission line and waveguide resonator.

\section{B. Hybrid Manufactured Waveguide Resonators and Filters}

Firstly, a $\lambda \mathrm{g} / 2$ resonator has been designed at $28.5 \mathrm{GHz}$ (Fig. 4.). Rings with elliptical irises, which unlike standard discontinuities with circular irises have no contact with the waveguide side walls, are made out of $0.1 \mathrm{~mm}$ thick copper. Dielectric insert is printed on Ultimaker 2+ Extended 3D printer [9] with $0.25 \mathrm{~mm}$ nozzle, having the vertical resolution (thickness of a single layer which is in waveguide H-plane) of $60 \pm 5 \mu \mathrm{m}$. Accuracy in an H-plane is $12.5 \mu \mathrm{m}$. The thickness of all the boundary layers are chosen to be minimum, whereas, the fill density is $30 \%$. Using effective medium approximation, the PLA dielectric is characterized by relative permittivity of $\varepsilon_{\mathrm{r}}=1.5$ and loss tangent $\tan \delta=0.003$, neglecting material anisotropy.

The elliptic cylinder air cavity inside the resonator with semi major axis of $2.75 \mathrm{~mm}$ and semi minor axis of $2.55 \mathrm{~mm}$ is used to reduce dielectric losses where there is field maximum in the resonator center. Since the filter insert is physically small, the volume filled with PLA is primarily determined by the mechanical requirements to have a firm structure. Apart from the passband, the response has two upper stopband attenuation poles at around $37 \mathrm{GHz}$, coresponding to two rings, and the first spurious passband is at $40 \mathrm{GHz}$. The simulated S-parameters of the hybrid manufactured resonator inside WR-28 metallic waveguide housing is shown in Fig. 4.

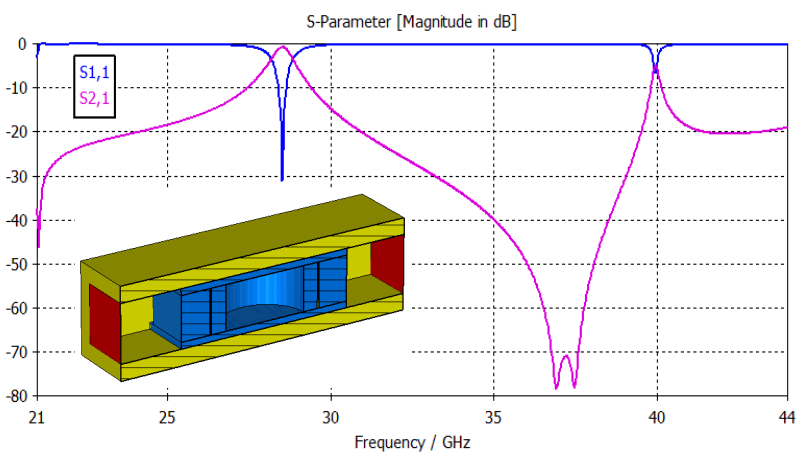

Fig. 4. Longitudinal cross section of the proposed resonator and its S-parameters.

The resonator length is $7.50 \mathrm{~mm}$. Ring elliptic iris semi major axis is $1.3 \mathrm{~mm}$ and semi minor axis is $0.8 \mathrm{~mm}$. The gap between the ring edges and the waveguide side walls both in E-planes and H-planes are $0.4 \mathrm{~mm}$. Resonator PLA insert is pictured in Fig. 6, showing its printing quality and relative size.

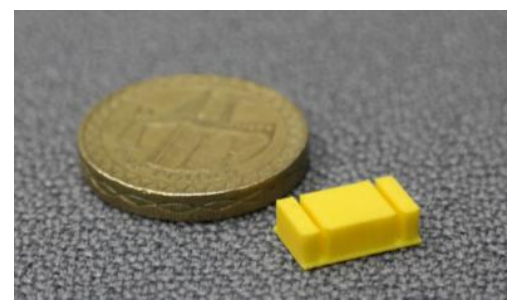

Fig. 5. Printer insert dielectric made using fused deposition modeling method.

A $28 \mathrm{GHz}$ PLA WR-28 ring with inserts waveguide housing for hybrid manufactured waveguide filter is shown in Fig. 6. The electroless plating used is again Ferro electronic materials silver 
conductor. The designed resonator and filter have been simulated using CST Microwave Studio of CST Studio Suite [10]. The simulated S-parameters of the bandpass filter are shown in Fig. 7.

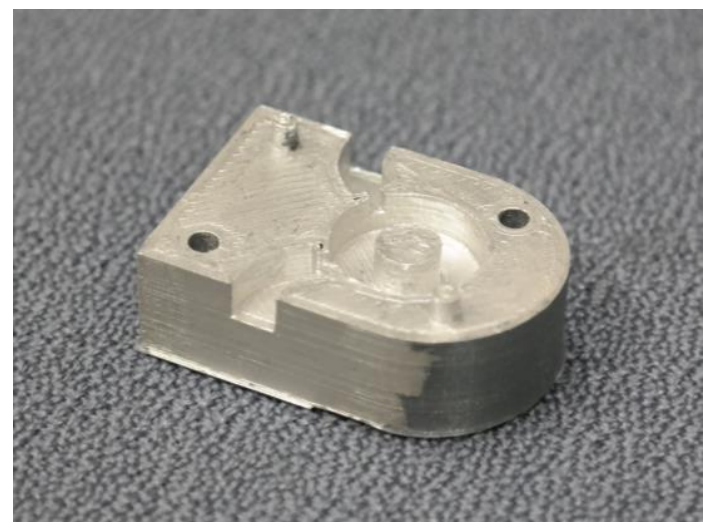

Fig. 6. Printed and metalized half-housing of the $28 \mathrm{GHz}$ hybrid manufactured waveguide filter.

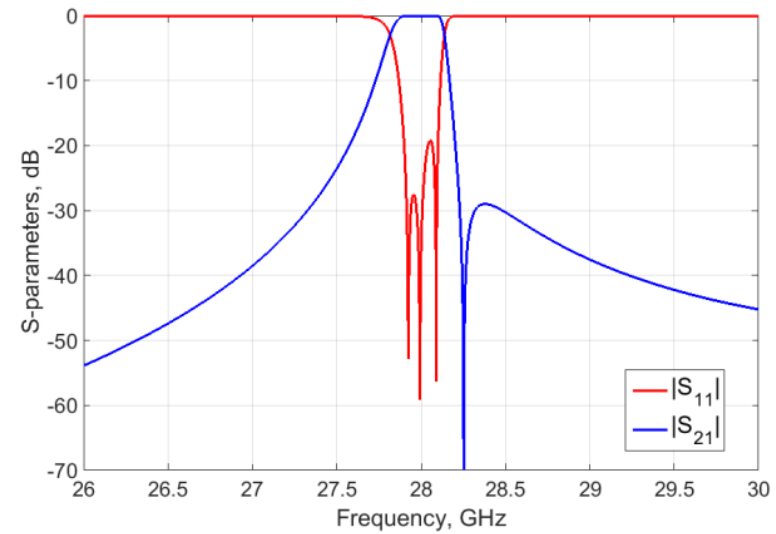

Fig. 7. Simulated S-parameters of the $28 \mathrm{GHz}$ hybrid manufactured waveguide bandpass filter.

\section{CONCLUSION}

mm-Wave 3D printed and hybrid manufactured waveguide resonators and bandpass filters have been presented. The flexibility of 3D printing, namely fused deposition modelling, and hybrid manufacturing made open possibility for geometrical versatility of low-cost waveguide resonator and filter components. A 3D printed WR-28 waveguide resonator has been fabricated and tested. Another waveguide resonator has been made, having PLA inside the housing. A $3^{\text {rd }}$ order quasi elliptic waveguide bandpass filter has been designed as well, with one transmission zero in the upper stopband.

\section{ACKNOWLEDGMENT}

This work was supported by UK India Education Research Initiative University Grants Commission under grant IND/CONT/G/16-17/63.

\section{REFERENCES}

[1] C. X. Wang et al., "Cellular architecture and key technologies for 5G wireless communication networks," IEEE Communications Magazine, vol. 52, no. 2, pp. 122-130, February 2014. doi: 10.1109/MCOM.2014.6736752

[2] F. Boccardi, R. W. Heath, A. Lozano, T. L. Marzetta and P. Popovski, "Five disruptive technology directions for 5G," IEEE Communications Magazine, vol. 52, no. 2, pp. 74-80, February 2014. doi: 10.1109/MCOM.2014.6736746

[3] “5G Spectrum Public Policy Position”, www.gsma.com, November 2016

[4] B. Zhang and H. Zirath, "3D printed iris bandpass filters for millimetrewave applications," Electronics Letters, vol. 51, no. 22, pp. 1791-1793, 1022 2015. doi: 10.1049/el.2015.2342

[5] J. Li, C. Guo, L. Mao and J. Xu, "3D printed bandpass filters using compact high-Q hemispherical resonators with improved out-of-band rejection," in Electronics Letters, vol. 53, no. 6, pp. 413-415, 3162017. doi: 10.1049/el.2016.4373

[6] F. Teberio et al., "Sensitivity analysis of a 3-D printed low-cost compact waveguide low-pass filter," 2016 46th European Microwave Conference (EuMC), London, 2016, pp. 249-252. doi: 10.1109/EuMC.2016.7824325

[7] E. de Rijk et. Al., "High Performance Additive Manufactured RF Waveguide and Antenna Components for Aeronautical and Space Applications", Additive Manufacturing for RF Passive Hardware Workshop, 46th European Microwave Conference (EuMC), London, UK, October 2016

[8] [Online], Available: http://www.hinkel-elektronik.de

[9] [Online], Available: https://ultimaker.com

[10] [Online], Available: http://www.cst.com 